\title{
On the Structure of Host-Guest Supramolecular
}

\section{Polymers}

Claudia Leggio, ${ }^{1,2}$ Massimiliano Anselmi, ${ }^{1}$ Alfredo Di Nola,${ }^{1}$ Luciano Galantini, ${ }^{* 1,2}$ Aida Jover,${ }^{3}$ Francisco Meijide, ${ }^{3}$ Nicolae Viorel Pavel, ${ }^{1,2}$ Victor Hugo Soto Tellini, ${ }^{3}$ and José Vázquez Tato ${ }^{3}$

${ }^{1}$ Dipartimento di Chimica, Università di Roma “La Sapienza”, P.le A. Moro 5, 00185 Roma, Italy.

${ }^{2}$ Research center SOFT-INFM-CNR, Università di Roma "La Sapienza”, P.le A. Moro 5, 00185 Roma, Italy.

${ }^{3}$ Departamento de Química Física, Facultad de Ciencias, Universidad de Santiago de Compostela, Avda. Alfonso X El Sabio s/n, 27002 Lugo, Spain,

E-mail addresses of the authors: leggio@caspur.it, m.anselmi@caspur.it, dinola@caspur.it, qfaida@caspur.it,_qfmeijide@lugo.usc.es,_v.pavel@caspur.it, vsoto@cariari.ucr.ac.cr, jvtato@lugo.usc.es

Corresponding author: Luciano Galantini, Dipartimento di Chimica, Università di Roma "La Sapienza", P.le Aldo Moro 5, 00185 Roma, Italy; telephone: (+39)-06-49913687, fax: (+39)-06490631; e-mail: 1.galantini@ @aspur.it 


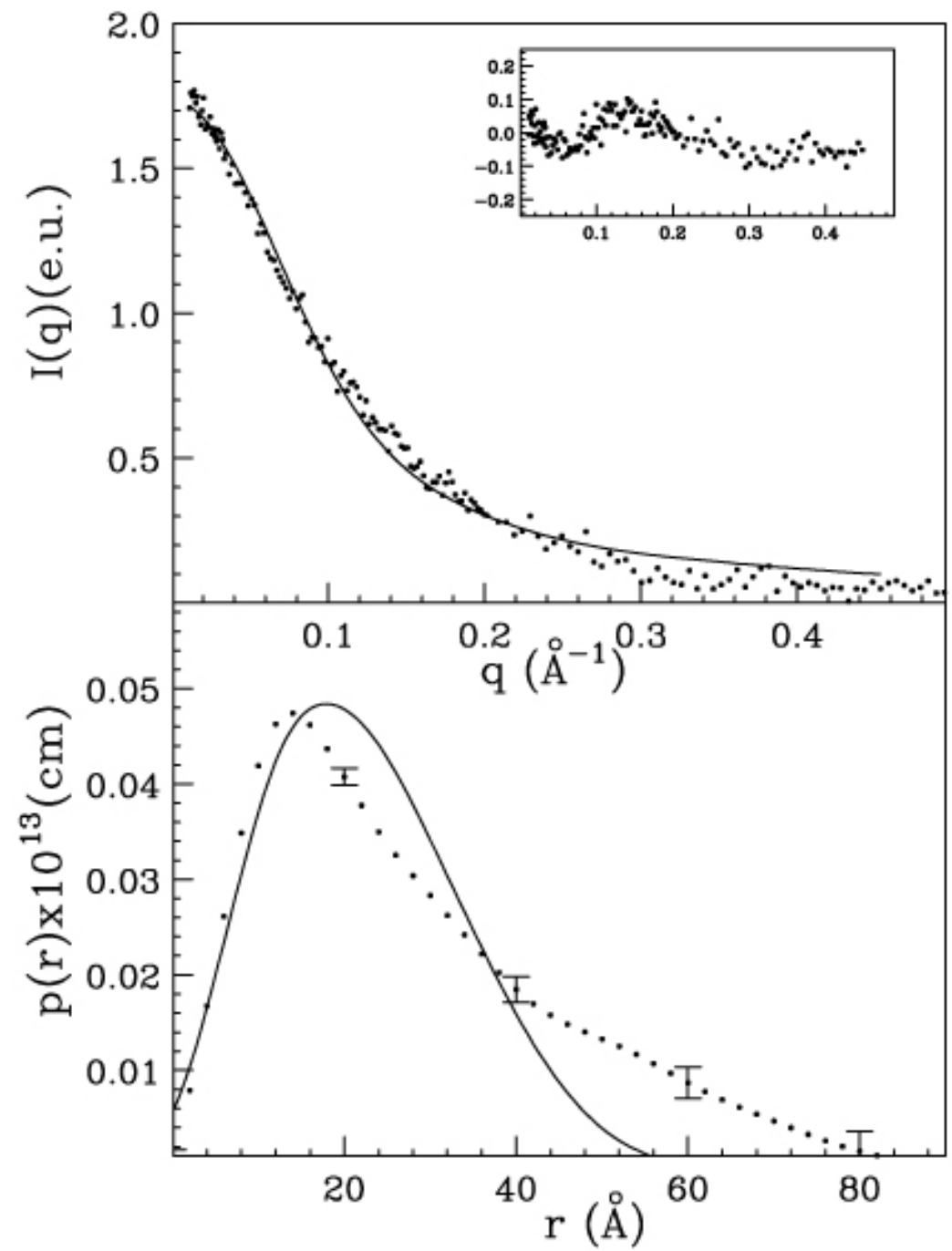

Figure 1S. SAXS experimental spectrum and extracted $p(r)$ function of the polymeric solution at polymer concentrations of $13.8 \mathrm{~g} \mathrm{~L}^{-1}$ (dots), and estimated patterns obtained by $\mathrm{RMC}_{\text {excy }}$ simulations without considering the carboxylic group in the overlap check (full lines). The intensity residuals are reported in the inset. 

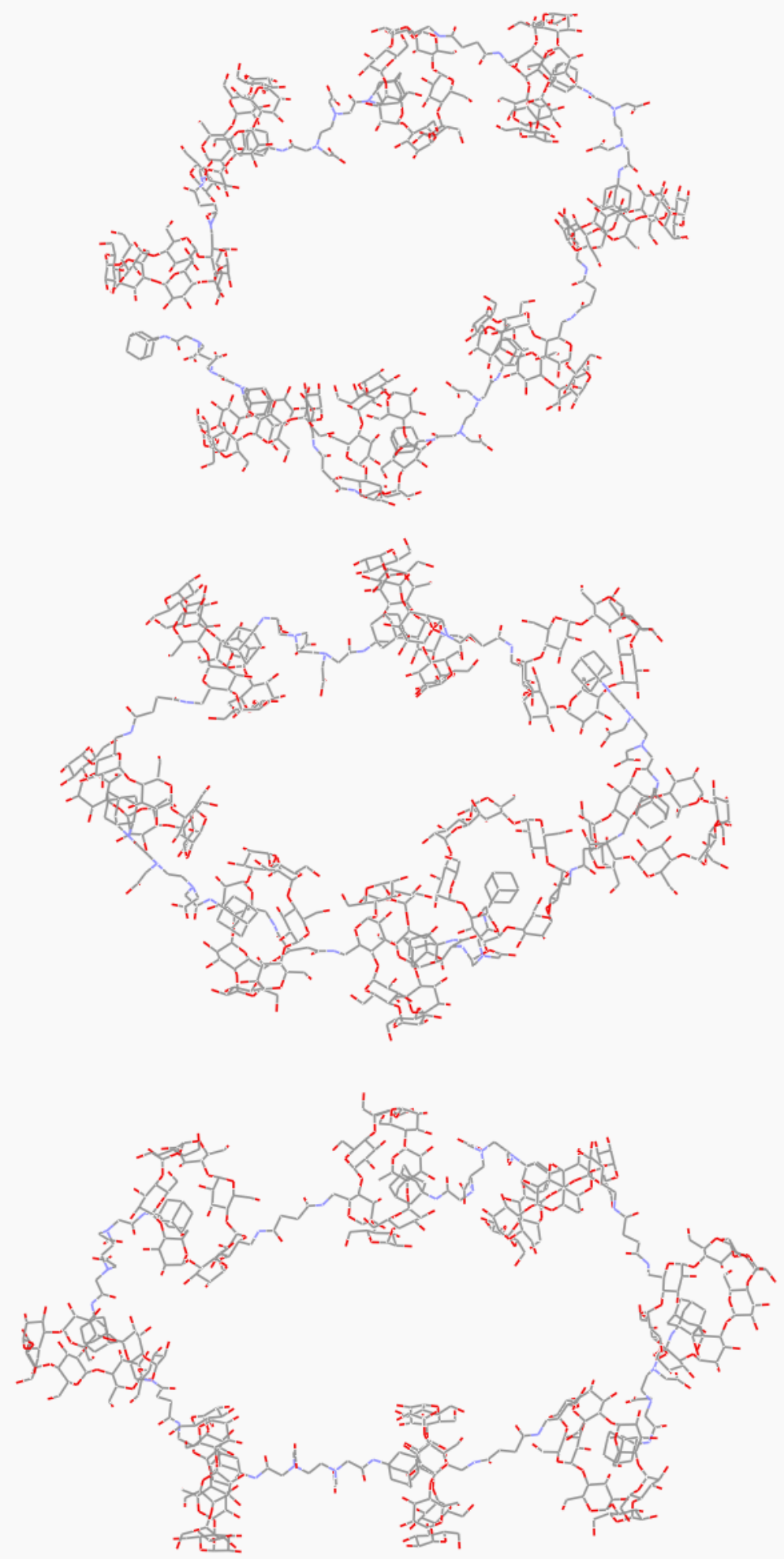

Figure 2S. Some accepted conformations obtained by RMCexcy simulations. 


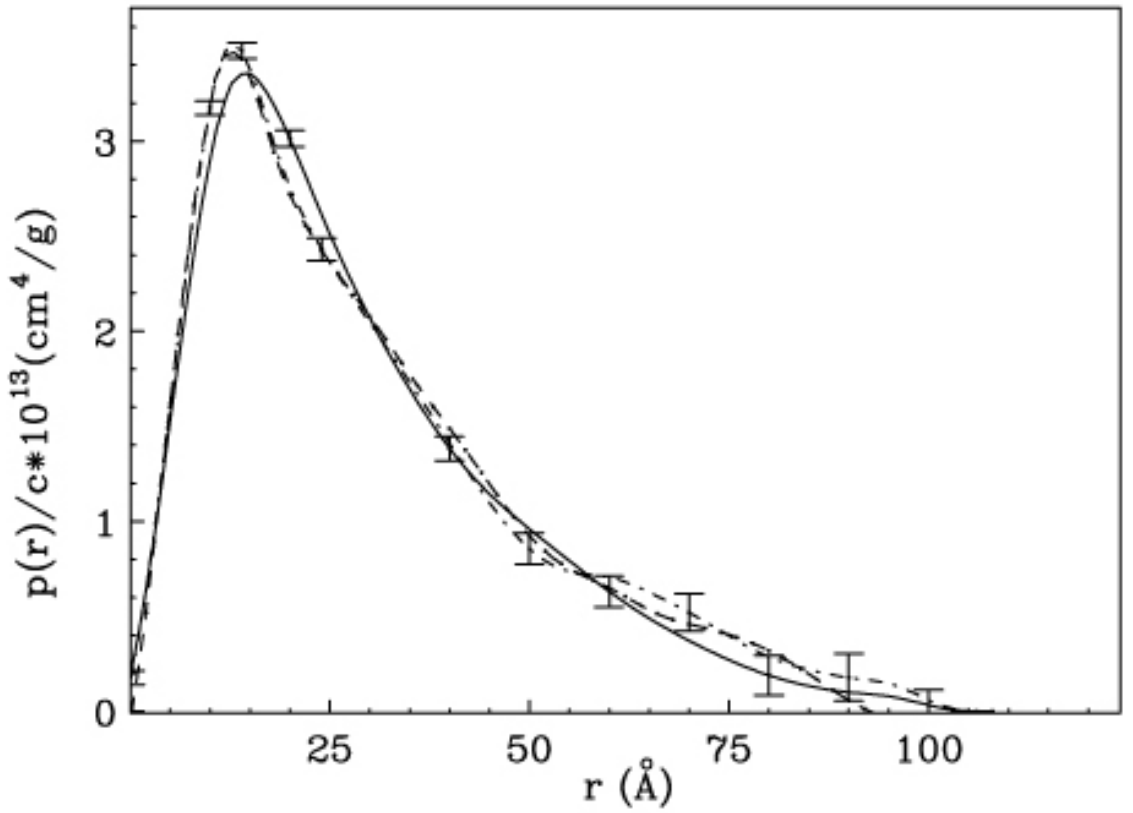

Figure 3S. $p(r)$ functions of polymeric samples with 1:1 (full line), 1.2:1 (dot dashed line) and 1:1.1 (dashed line) $\mathrm{Ad}_{2}: \beta C \mathrm{D}_{2}$ molar ratios. 